\title{
Trabalho artesanal e cooperado: realidades, mudanças e desafios
}

Paulo Fernandes Keller Doutor em Ciências Humanas - Sociologia (Universidade Federal do Rio de Janeiro) Professor na Universidade Federal do Maranhão paulo.keller@pq.cnpq.br

\begin{abstract}
Resumo $\mathrm{O}$ artigo tem por objetivo apresentar singularidades da realidade socioeconômica e das transformações do trabalho artesanal a partir de estudo de caso da Cooperativa das Artesãs dos Lençóis Maranhenses (Artecoop) no município de Barreirinhas (MA). Faz uma análise das relações de trabalho e de produção das artesãs cooperadas e seu enraizamento em redes de relações socioeconômicas e institucionais. Analisa o impacto de políticas governamentais e da inserção das artesãs e de seus produtos no mercado capitalista e na cadeia de valor do artesanato. A introdução da visão empreendedora, a importância de adequar o produto ao mercado e a cooperativa como um meio (empresa) para alcançar a competitividade são pontos destacados. Em que medida estas mudanças alteram a identidade do trabalho artesanal? Como trabalhadoras do artesanato produzindo para viver na informalidade e na precariedade enfrentam o desafio de se tornarem empreendedoras através da ação cooperada?
\end{abstract}

Palavras-chave: artesanato; cooperativa; trabalho artesanal; economia do artesanato; Maranhão.

\section{Introdução}

$\mathrm{N}$ ESTE ARTIGO, DisCUTE-SE O TEMA DO TRABALHO ARTESANAL COOperado na sociedade contemporânea; investigam-se as realidades sociais e econômicas do trabalho artesanal com enfoque nas relações sociais de produção e seu ambiente social; destaca-se a importância da organização de associações e cooperativas na economia do artesanato brasileiro presente nas análises de estudiosos e nas pautas das políticas de fomento. Assim, enfocam-se as práticas socioeconômicas das artesãs cooperadas em seu ambiente sociocultural, econômico e institucional.

Em nossa perspectiva, a cooperação existe em diferentes contextos sociais e históricos e constitui uma prática social, cultural e econômica. Há diversidades de práticas sociais de cooperação, e aqui enfocamos as práticas de cooperação na heterogênea realidade do artesanato brasileiro contemporâneo. Temos como referência a perspectiva marxiana, que assim define cooperação: "Chama-se cooperação a forma de trabalho em que muitos trabalham juntos, de acordo com um plano, no mesmo processo de produção ou em processos de produção diferentes mas conexos" (Marx, 1975, p. 374). A definição de cooperação nesta perspectiva independe de qualquer modo de produção e enfoca o valor de uso da cooperação no capitalismo. A relação de cooperação enquanto uma relação de valor, vista por Karl Marx (1975) em termos sociais. 
Em nossa investigação do trabalho e da produção artesanal na sociedade contemporânea com base em estudo de caso da Cooperativa das Artesãs dos Lençóis Maranhenses (Artecoop) no município de Barreirinhas (MA), constatamos práticas de cooperação no núcleo familiar e nas relações de vizinhança. Existem práticas cooperativas na produção artesanal que ocorrem predominantemente no ambiente doméstico (sistema de produção domiciliar), entre as artesãs e seus familiares (fillha e marido principalmente), assim como no ambiente comunitário e de vizinhança (pequena oficina coletiva), entre as artesãs de povoado. As artesãs da Artecoop estão enraizadas nestas redes de produção locais e cooperam sobretudo na comercialização de seus produtos.

$\mathrm{O}$ artigo tem por objetivo apresentar singularidades da realidade socioeconômica e das transformações do trabalho artesanal com base em estudo de caso da Artecoop no município de Barreirinhas (MA), fazendo uma análise das relações de trabalho e de produção das artesãs cooperadas na Artecoop e sua inserção em redes de relações socioeconômicas e institucionais. Destaca-se o enraizamento das artesãs cooperadas nas redes de produção e de comercialização do artesanato - a cadeia de valor do artesanato - e na difícil realidade socioeconômica local marcada pelo trabalho informal e precário das artesãs. O trabalho de produção de artesanato à base de fibra de buriti no município é praticado predominantemente por mulheres. A maioria das artesãs locais produz em uma forma de núcleo familiar de produção de artesanato em que se configura o trabalho artesanal em domicílio. As artesãs cooperadas da Artecoop estão ligadas à cultura da agricultura familiar e produzem artesanato de valor tradicional e cultural utilizando como matéria-prima a fibra de buriti, uma palmeira típica da região.

$\mathrm{Na}$ análise das mudanças do trabalho artesanal, destacamos a inserção das artesãs da Artecoop em redes de relações com o mercado (turismo e moda) e com órgãos governamentais e agências de fomento. $\mathrm{O}$ artesanato baseado em fibra de buriti é uma atividade exercida por um grande número de mulheres no município de Barreirinhas (MA). Estimamos este número entre oito e dezessete mil artesãs ${ }^{1}$.
Em geral, as artesãs comercializam seus produtos informalmente e de forma não cooperada com comerciantes locais ou de fora, conhecidos como intermediários ou 'atravessadores'. Estes adquirem os produtos artesanais fornecidos pelas artesãs por preços subavaliados (comércio não justo). Os comerciantes 'atravessadores' tiram vantagens da situação social das artesãs locais. A maioria delas não tem conhecimento do real valor de seu trabalho e de seu produto e vive em condições sociais e econômicas difíceis. Muitas têm necessidade de vender imediatamente seus produtos para adquirir produtos de primeira necessidade.

No momento atual, a cooperativa associa $26 \mathrm{mu}-$ lheres que produzem em diversos povoados do município de Barreirinhas (MA). O grupo de artesãs da qual a Artecoop se originou foi um grupo amplo que reunia artesãs que participavam desde 2001 de diversas ações do SEBRAE/MA por intermédio do Projeto Artesanato em Fibra de Buriti. Deste grupo, cerca de 98 mulheres se uniram e formaram uma Associação de Artesãs que, posteriormente, em 2006, se transformou na Artecoop. A cooperativa tem o apoio do Projeto Talentos do Brasil. do Ministério do Desenvolvimento Agrário (MDA). Por meio de diversos apoios e parcerias de órgãos governamentais e agências de fomento (em especial os Programas do MDA e do SEBRAE), as artesãs têm obtido maior qualificação e acesso a novos mercados (moda - nacional e global), além do mercado local (turismo ecológico).

As transformações no mundo do trabalho artesanal têm suas próprias dinâmicas em razão da peculiaridade e heterogeneidade do artesanato. Estas dinâmicas em parte se diferenciam das dinâmicas do mundo do trabalho industrial, o que não significa que não estejam articuladas às mudanças na economia e na sociedade capitalista. Os trabalhadores do setor artesanal, sejam eles do mundo urbano ou rural, são considerados trabalhadores autônomos que, em geral, vivem na informalidade e em condições bastante precárias, sem acesso a direitos sociais básicos. Uma atividade ainda não regulamentada. ${ }^{2}$ Há heterogeneidade dentro da economia do artesanato, em que podemos encontrar uma diversidade de situações de trabalho e de formas de produção. $\mathrm{O}$ artesanato é diverso, seja pelo tipo de matéria-prima utilizada, pela técnica, pelo produto que é confeccionado, seja pelas diversas realidades vividas pelos artesãos e artesãs.

1 Dados oficiais sobre a realidade do trabalho e da economia do artesanato no Brasil são escassos. Nesta estimativa, foram utilizados dados oficiais atuais do município de Barreirinhas disponíveis no site do IBGE. Segundo o IBGE, a população do município em 2010 era composta de 54.991 habitantes, sendo 26.832 mulheres. Neste trabalho de campo, o autor indagou diversas pessoas sobre o número de artesãs no município: de cada três mulheres, quantas seriam artesãs? Todos respondiam que seriam as três. Para a estimativa, o autor calculou que o número das artesãs produtivas ou ativas economicamente estaria entre 1/3 e 2/3 do universo da população feminina, chegando a uma cifra aproximada que oscila entre 8.944 e 17.888 artesãs. Dados do IBGE disponíveis no site: http://www.ibge.gov.br/cidadesat/painel/painel.php?codmun=210170\# (2011). 2 Tramita no Congresso Nacional - Comissão de Desenvolvimento Econômico, Indústria e Comércio - o Projeto de Lei n. 3.926 (2004) de autoria do Deputado Eduardo Valverde (PT/RO). O Projeto de Lei institui o Estatuto do Artesão, define a profissão de artesão, a unidade produtiva artesanal, autoriza o poder executivo a criar o Conselho Nacional do Artesanato e o Serviço Brasileiro de Apoio ao Artesanato e dá outras providências. Dados disponíveis em: http://www.camara.gov.br/proposicoesWeb/fichadetramitacao?idProposicao=484749 (Consulta realizada em 27/09/2011). 
O crescimento do número dos trabalhadores que tem no artesanato sua principal fonte de renda (economia substantiva) é atribuído ao crescimento do desemprego tanto no ambiente urbano como no rural. Nesse sentido, pode-se dizer que o artesanato é uma alternativa de sobrevivência para o enfrentamento das consequências das transformações no trabalho em âmbito geral, as quais vêm promovendo desemprego e precarização nas relações de trabalho. Dessa forma, as artesãs aproveitam a experiência e o conhecimento adquiridos ao longo do tempo e, com isso, garantem uma renda mensal (muitas vezes inferior ao salário mínimo vigente) e ao mesmo tempo reproduzem a cultura, a tradição e os costumes regionais.

Vários fatores têm levado a transformações no mundo do trabalho artesanal e na economia do artesanato. Neste artigo, analisamos as mudanças no mundo do trabalho artesanal tradicional atribuído a dois fatores, a seguir: primeiro, o crescimento da produção voltada para o mercado tanto local (turismo) como distante (moda), indo além da simples produção para o consumo próprio e de caráter utilitário; e, segundo, o impacto da intervenção de políticas governamentais, em que se destacamos a ênfase na organização associativa e cooperativa e na capacitação das artesãs para valorizar seu produto e vencer o comerciante 'atravessador'; a introdução de uma consciência ambiental entre artesãs e artesãos; a introdução de uma visão empreendedora e a ênfase na transformação do artesão em um empresário e do artesanato em um negócio; a utilização da cooperativa como um meio (empresa) para alcançar competitividade; e ênfase na necessidade de aprimorar e adequar o produto ao mercado consumidor onde surge a relação entre artesão e designer, sendo que este atua para adequar o produto às exigências do mercado consumidor.

Levantamos algumas questões: em que medida emergem novas formas de trabalho e de produção do artesanato que utiliza a fibra de buriti como matéria-prima em função das relações das artesãs da Artecoop com o mercado e do impacto da intervenção de políticas governamentais? Até que ponto estas novas práticas resgatam, mudam ou recriam a identidade do trabalho artesanal? Como trabalhadoras do artesanato produzindo para viver na informalidade e na precariedade enfrentam o desafio de se tornarem empreendedoras por meio da ação cooperada (cooperativa)?

Salienta-se que este estudo é parte integrante do projeto Trabalhadores Artesãos na Sociedade Contemporânea: uma Análise do Trabalho e da Produção Artesanal à base de Fibra de Buriti nas Cidades de Barreirinhas e Tutóia, no Maranhão, que conta com o apoio do CNPq e da FAPEMA. A investigação teórica empírica articula de forma combinada ferramentas analíticas dos subcampos da sociologia do trabalho e da sociologia econômica. A metodologia de pesquisa faz uma triangulação do estudo de caso com a pesquisa documental, a observação direta realizada em trabalho de campo e o uso da entrevista semidirigida somada a elementos da entrevista narrativa. Nossas análises estão baseadas em pesquisa qualitativa que instrumentaliza fundamentalmente dados qualitativos e, eventualmente, dados quantitativos.

\section{Trabalho e produção artesanal}

O trabalho artesanal surge como tema importante em razão de ser uma atividade considerada tradicional e ao mesmo tempo presente na sociedade contemporânea. Trata-se de um trabalho que tem tanto uma dimensão criativa e simbólica quanto econômica e mercantil.

Alvim, em seu estudo sobre a "arte do ouro" de Juazeiro do Norte, já alertava para o fato de que

A relação do artesanato com a tradição faz com que
muitas vezes grupos sociais que tiram do artesana-
to seus meios de existência sejam catalogados como
partes de uma sociedade tradicional que se define por
oposição a uma sociedade moderna [...]. No entanto,
ver no artesanato resquícios de uma sociedade tradi-
cional é esquecê-lo como contemporâneo e minimi-
zá-lo em sua importância na medida em que é através
das chamadas atividades artesanais que parte signifi-
cativa da população sobrevive. (Alvim, 1983, p. 49 )

O trabalhador artesanal é contemporâneo e sua presença na sociedade e na economia de hoje se faz de modo particular. Trata-se não apenas de um meio de sobrevivência, mas de uma atividade que demanda habilidades e capacidades específicas, consideradas não apenas manuais, mas, sobretudo, criativas. ${ }^{3}$

Para Marx (1975), o trabalho, em seu sentido abstrato, constitui um intercâmbio entre homem e natureza por meio de um dispêndio de energias físicas e mentais. $\mathrm{O}$ trabalho é um processo de que participam o homem e a natureza, quando o ser humano "Põe em movimento as forças naturais de seu corpo, braços

$3 \mathrm{Na}$ atualidade a economia do artesanato é parte da economia e da indústria criativa. O documento da UNIDO (2002, p. 14) afirma que as indústrias criativas "constituem um campo complexo e heterogêneo que vai desde os produtos artesanais até as artes visuais e performáticas, a indústria da música, do cinema e produção audiovisual, assim como multimídia incluindo arte digital, publicidade e entretenimento e representa um dos setores mais dinâmicos nos negócios econômicos globais". 
e pernas, cabeça e mãos, a fim de apropriar-se dos recursos da natureza, imprimindo-lhes forma útil à vida humana" (Marx, 1975, p. 202).

Marx enfatiza que o "trabalho humano" é essencialmente criativo,

[...] o que distingue o pior arquiteto da melhor abelha é que ele figura na mente sua construção antes de transformá-la em realidade. No fim do processo de trabalho aparece um resultado que já existia antes idealmente na imaginação do trabalhador. Ele não transforma apenas o material sobre o qual opera; ele imprime ao material o projeto que tinha conscientemente em mira, o qual constitui a lei determinante do seu modo de operar e ao qual tem de subordinar sua vontade. (Marx, 1975, p. 202)

Contudo, a economia e a ideologia capitalista dissociam o saber do fazer, o trabalho intelectual do manual (Marx, 1975). Assim, os artesãos contemporâneos tornam-se - em diversas situações - uma espécie de guardiões de conhecimentos relativos a processos de produção tradicionais no Brasil e em outras partes do mundo.

Nos dias atuais, a produção artesanal atende aos novos nichos de mercado, a partir do ressurgimento do interesse e da valorização do objeto artesanal e natural. O produto artesanal é diferenciado pela carga cultural e pela identidade societária que carrega, ou, em uma linguagem estritamente econômica, um produto com um valor agregado. Apesar da informalidade da produção e da precarização das condições de trabalho, o produto artesanal ganha destaque em uma sociedade de mercadorias globalizadas e padronizadas.

Canclini afirma que houve um crescimento da participação do artesanato na economia (dos bens simbólicos e folclóricos) e indica alguns dos principais motivos para este fato:

Os estudos sobre artesanato mostram um crescimento do número de artesãos, do volume da produção e de seu peso quantitativo: um relatório da SELA calcula que os artesãos dos quatorze países latino-americanos analisados representam 6\% da população geral e 18\% da população economicamente ativa. Uma das principais explicações do incremento, dada tanto por autores da área andina quanto meso-americana, é que as deficiências da exploração agrária e o empobrecimento relativo dos produtos do campo impulsionaram muitos povos a procurar na venda do artesanato o aumento de sua renda [...]. O desemprego é outro dos motivos pelos quais esta aumentando o trabalho arte- sanal, tanto no campo quanto nas cidades, deslocando para esse tipo de produção jovens procedentes de setores socioeconômicos que nunca trabalharam nesse ramo. (Canclini, 2008, p. 215)

Sobre o artesanato enquanto "modelo idealizado", Mills destaca o domínio do artesão sobre todas as etapas do processo de trabalho, ou seja, um único trabalhador exerce todas as funções ou tem consciência de sua parte no todo:

O que é realmente necessário para o trabalho-como-artesanato, contudo, é que o vínculo entre o produto e o produtor seja psicologicamente possível; se o produtor não possui legalmente o produto, deve possuí-lo psicologicamente [...]. O artesão tem uma imagem do produto acabado, e mesmo que não o faça inteiro, vê o lugar de sua parte no todo e, por conseguinte, compreende o significado de seu esforço em termos desse todo. (Mills, 2009, p. 60)

Sennett (2009) explora o vínculo entre "mão" e "cabeça" e a imagem da "mão inteligente" para ressaltar as relações entre concepção (artesão criativo) e execução (artesão habilidoso). No mundo moderno, com o crescimento da produção industrial, ocorre o declínio das oficinas artesanais. $\mathrm{O}$ advento da produção capitalista, com sua divisão do trabalho complexa, vai dissociar e subdividir as diversas funções do processo de trabalho. Este processo deixa de ser simples produção de objetos úteis para se tornar produção de valor (Marx, 1975, p. 584).

A análise de Marx (1975) ajuda a refletir sobre as formas coletivas de produção artesanal. O trabalho artesanal na cooperativa Artecoop de Barreirinhas não constitui trabalho assalariado, por ser uma forma de trabalho autônomo ou por conta própria 4 . Contudo, as artesãs, como trabalhadoras cooperadas, produzem uma mercadoria (objeto artesanal) que tem valor (mercantil, cultural e simbólico) e que circula ao longo da cadeia de valor do artesanato. Atendem a mercados que funcionam segundo a lógica econômica capitalista. As artesãs cooperadas estão imersas em uma produção que opera de forma informal e precária e ligada ao mercado capitalista formal.

Para Alves e Tavares,

O estudo das atividades informais deve estar articulado ao processo dinâmico e contraditório de acumulação de capital, que envolve deste os trabalhadores informais tradicionais até os pequenos proprietários por conta própria que atuam em várias áreas da economia. (Alves e Tavares, 2006, p. 434) 
Nesse sentido, ressaltamos as conexões entre o tradicional trabalho informal e precário das artesãs com o sistema econômico formal; as ligações entre o trabalho artesanal informal realizado em domicílio - que em várias situações utiliza o trabalho de algum outro membro da família - com o mercado capitalista formal.

Alves e Tavares (2006, p. 430-442) argumentam que "a economia informal, em suas várias formas, mantém relações intrínsecas com as empresas capitalistas [e que] há estreitos vínculos entre o trabalhador informal e o processo de acumulação".

Os estudos do antropólogo Ricardo Gomes Lima do Museu do Folclore (Centro Nacional de Folclore e Cultura Popular/MinC) sobre o artesanato constituem uma referência teórica importante e fonte para diversas reflexões teóricas quando o tema é o artesanato. Em sua perspectiva, os artesãos são produtores tanto de objetos quanto de cultura.

Quando a questão é a produção artesanal, Lima (2005) afirma que existem dois discursos, sendo que o primeiro advoga a "conservação" do objeto artesanal, dotado de estética perfeita que refletiria o gosto do seu produtor, nas condições em que foi produzido, e o segundo, a "adequação" do objeto artesanal aos tempos contemporâneos, "tempos que preconiza a transformação de sua forma, a criação de um novo design ("refinado") como condição para garantir mercado". Lima (2005) afirma que há vários atores sociais nesta discussão e um sentido de "buscar condições" que garantam ao trabalho artesanal maior geração de renda e ampliação do mercado, respeitando os artesãos e os valores populares e culturais.

O objeto artesanal é produto do fazer humano (fazer manual), em que o uso de ferramentas e instrumentos de trabalho no manuseio da matéria-prima (objeto de trabalho) é subsidiário à vontade do criador, usando basicamente as mãos. Característica importante destacada por Lima (2005) é a liberdade do artesão para definir o ritmo da produção, a matéria-prima e a tecnologia utilizadas e a forma que pretende dar ao produto (produto de sua criação e de seu saber fazer).

Lima (2005) destaca que "o artesanato não é mera mercadoria". Trata-se de um produto diferenciado pela sua dimensão econômica e cultural. Um produto que integra um sistema de valores culturais da comunidade ou região. Bourdieu (1996, 2004) não trata especificamente do artesanato, mas do "mercado dos bens simbólicos". Os produtos culturais e simbólicos, para Bourdieu, trazem este "duplo valor": cultural e mercantil:

Esse universo relativamente autônomo [...] dá lugar a uma economia às avessas, fundada, em sua lógica específica, na natureza mesma dos bens simbólicos, realidades de dupla face, mercadorias e significações cujo valor propriamente simbólico e o valor mercantil permanecem relativamente independentes. (Bourdieu, 1996, p. 162)

Lima (2005) também afirma que "artesanato não é imutável". Se o artesanato é passível de mudança, a questão é 'como ocorre' a mudança e 'em que medida' o artesão e suas organizações são atores atuantes na condução deste processo de mudança. A questão da coordenação das atividades de trabalho e de produção deve se estender para todas as atividades que integram a "cadeia de valor do artesanato". ${ }^{5}$ A atuação ativa do artesão e de suas organizações no processo de mudança envolve o desafio de conhecer as diversas etapas de trabalho e de produção que integram a cadeia do produto artesanal, desde o design, passando pela manufatura até a comercialização, o marketing e o consumo.

\section{Trabalho cooperado na economia do artesanato no Maranhão: a Artecoop e a produção artesanal a base de fibra de buriti em Barreirinhas (MA)}

Alguns indicadores importantes do artesanato no Brasil foram apresentados na Tabela Economia Feita à Mão, publicada em matéria do Jornal Valor Econômico: "Gestão - Programas do SEBRAE pretendem agregar valor à arte regional - Profissionalizar é a ordem no universo dos artesãos" (TIAGO, 2010).Estima-se um número de 8,5 milhões de artesãos ativos no Brasil. Nesta economia produzida de forma artesanal, seriam movimentados $\mathrm{R} \$ 52$ bilhões ao ano. A renda média da atividade seria de $\mathrm{R} \$ 515,00$. No Maranhão, o SEBRAE estima que cerca de 50 mil famílias tenham o artesanato como sua fonte de renda. Indícios de pesquisa obtidos em trabalho de campo revelam que a renda mensal das artesãs associadas na Artecoop oscila entre um e dois salários minimos em períodos de muita demanda ou menos que um salário minimo em periodos de pouca demanda.

Em nossas investigações, destacamos as relações sociais e econômicas das artesãs ao longo da cadeia do produto e sua imersão na sociedade e na economia do artesanato local. Buscamos aplicar a análise da cadeia de valor ou cadeia da mercadoria (Keller, 2006) ao conjunto das relações de trabalho e de produção pre-

5 Por cadeia de valor consideramos o conjunto das atividades econômicas interligadas que compõem a cadeia do produto, desde o design, passando pela manufatura, o marketing e a comercialização, até o consumo final (Keller, 2006). 
sente na economia do artesanato. Uma cadeia específica para um produto de valor específico que conjuga diversos valores: social, cultural, simbólico, econômico e mercantil.

As atividades de trabalho e de produção na cadeia de valor do artesanato articulam os três elementos do processo de trabalho (Marx, 1975): o trabalho do artesão com sua capacidade de criar e produzir ("mão criativa"). Sua capacidade de criar o produto a partir de elementos sociais e culturais parte do patrimônio sócio-histórico e cultural coletivo e dos saberes tradicionais. Sua capacidade de produzir usando técnicas e saberes práticos parte desta herança social e cultural coletiva; a matéria-prima, neste caso a fibra de buriti, uma matéria que é parte do ecossistema natural (buritizais) e parte da cultura local; as tecnologias, as ferramentas e as técnicas do artesão.

A matéria-prima principal é a fibra das folhas da palmeira de buriti, de qual se extrai o material utilizado para a confecção da maior parte dos produtos fabricados pelas artesãs. As atividades de trabalho que integram o processo de produção do produto artesanal à base de fibra de buriti são: primeira, a extração do 'olho' do buriti; segunda, a extração do linho ou fibra; terceira, o beneficiamento da fibra; quarta, o tingimento da fibra; e quinta, a produção ou confecção das peças utilizando diversas técnicas.

Os saberes e as habilidades destas trabalhadoras são transmitidos de geração para geração no seio das famílias e na comunidade local. As atividades de extração do 'olho' (broto) da palmeira do buriti na região dos Lençóis Maranhenses são realizadas em sua grande maioria por homens como uma atividade econômica secundária e informal. Existe uma clara divisão sexual do trabalho nesta produção artesanal, os homens extraindo a matéria-prima da natureza (extração do 'olho' do buriti) e as mulheres produzindo o artesanato (extração e beneficiamento da fibra e confecção do produto).

As relações de troca dos homens extrativistas com as mulheres artesãs - para quem eles fornecem e/ou vendem a matéria-prima para o trabalho artesanal envolvem a dimensão econômica e cultural. Estas trocas estão ligadas a relações de amizade e de vizinhança, assim como a relações de parentesco no interior das comunidades nos povoados.

Após adquirir o 'olho' neste mercado informal ${ }^{6}$, as artesãs, munidas de suas ferramentas ${ }^{7}$, extraem o linho. A extração do linho consiste em abrir o 'olho', retirando a parte inferior denominada linho ou fi- bra. O beneficiamento consiste em cozinhar, lavar e secar o linho. O tingimento tem a finalidade de colorir o linho usando-se tinturas naturais obtidas de plantas regionais (urucum, salsa, mangue, entre outras). Os produtos confeccionados pelas artesãs são: bolsas, chapéus, sacolas, toalhas, caminhos de mesa etc. Elas utilizam técnicas manuais como crochê, 'ponto batido', macramê, entre outros.

A comercialização local dos produtos artesanais ocorre nas lojas que ficam na área urbana da cidade de Barreirinhas, onde há movimentação de turistas, nas casas das próprias artesãs nos povoados ou em pequenos pontos de venda ao longo dos roteiros turísticos. Em virtude da precariedade das condições de vida destas trabalhadoras, segundo relato de artesãs em trabalho de campo, a prática do escambo - quando a artesã troca seu produto por gênero de primeira necessidade com comerciante 'atravessador' - ocorria com frequência e ainda é possível que seja praticado por alguma artesã em algum povoado. Em geral, o produto artesanal é desvalorizado e subavaliado pelos comerciantes chamados de intermediários ou 'atravessadores'.

As atividades do Programa de Artesanato do SEBRAE na região tiveram início em 2000, quando eram realizadas reuniões com as artesãs de vários povoados da região. Segundo relato de uma artesã ex-presidente da Artecoop, eram reuniões de capacitação que tratavam da melhoria do produto e de formas de profissionalizar a atividade, realizando dinâmicas e cursos. As artesãs associadas começaram a ter acesso a feiras de comercialização de artesanato em outros estados e foram passando a encarar o artesanato como um negócio. Primeiro surgiu uma associação de forma embrionária que depois, em 2006, se transformou na Cooperativa das Artesãs dos Lençóis Maranhenses (Artecoop) criada com 98 artesãs. ${ }^{8}$

Vejamos o relato das artesãs sobre este momento:

Em 2001 o SEBRAE apareceu aqui em Barreirinhas. Quando o SEBRAE apareceu aqui fez as oficinas. E aí nós juntamos. Vimos que só a pessoa trabalhar individual nas suas casas. A gente não tava tendo lucro. Por que cada qual fazia sua peça de produto. Vendia muito pros atravessadores. $\mathrm{O}$ atravessador comprava da gente. Humilhava as artesãs. Ai eu vi aquela necessidade. Que aquilo não tava sendo um sucesso pra gente. Pra eles tava certo porque eles ganhavam o dinheiro deles e a gente dava quase nada. Trabalhava muito. Sacrificava muito. E nós não tava ganhando quase nada.

6 Durante trabalho de campo em janeiro de 2010, registrei que um 'olho' grande custava para as artesãs entre $R \$ 2,00$ e $R \$ 2,50$ e um 'olho' pequeno podia variar de $\mathrm{R} \$ 0,50$ a $\mathrm{R} \$ 1,00$.

$7 \mathrm{Na}$ extração de linho utilizam uma pequena faca.

8 Segundo relato das artesãs entrevistadas, problemas de gestão ocorridos nos primeiros momentos da Cooperativa provocaram perdas financeiras para as artesãs cooperadas, o que teria provocado a saída de diversas delas. 
O produto era muito barato mesmo. (Artesã da Artecoop)

Eu trabalhava como artesã individual. Todas nós aqui. Ai a partir de 2000 a gente andava fazendo produto da gente. Andava ai vendendo nas lojas. Muitas das vezes eles não queriam, diziam que nosso produto não era bem feito. E o Sebrae veio aqui para Barreirinhas. Nessa época não tinha nem agência. E começou a fazer reuniões, começou a fazer reuniões nos povoados [...]. E ai veio a necessidade de criar a cooperativa para ter a nota fiscal. Em 2006 a agente registrou a cooperativa. (Artesã da Artecoop)

Um dos principais eixos articuladores das políticas governamentais voltadas para o artesanato é a organização dos trabalhadores e o estímulo para que atuem de forma associada ou cooperada. Estudos pioneiros sobre o artesanato da década de 1980 já ressaltavam a importância das associações e cooperativas na economia do artesanato.

Vives (1983, p. 144) enfatiza que a vida de grande parte destas trabalhadoras fica à margem do sistema previdenciário e destaca que a "formação de cooperativas" dentro desta economia favoreceria os trabalhadores a vencerem o "tradicional comerciante atravessador", que lucra com a intermediação entre os produtores e o mercado consumidor. No caso específico da economia do artesanato, a cooperativa surge como uma forma de organização social e econômica com o papel de superar a subordinação à empresa comercial que faz a intermediação entre os produtores individuais e o mercado consumidor. Contudo, indícios de pesquisa obtidos no trabalho de campo demonstram que parcela muito pequena dos artesãos e artesãs atuam de forma associada ou cooperada. Estes dados suscitam novas questões sobre os interesses e motivações da ação cooperada dos artesãos em contextos sociais e econômicos específicos.

As artesãs associadas à Artecoop comercializam seus produtos no varejo e no atacado, ${ }^{9}$ diretamente na loja da cooperativa na parte urbana de Barreirinhas ou por encomenda de comerciantes de grandes centros urbanos brasileiros por intermédio da Cooperativa Nacional Marca Única (Cooperunica). ${ }^{10}$ A Cooperunica é uma associação de cooperativas e associações de artesãs que tem vínculo com o Programa Talentos do Brasil, do Ministério do Desenvolvimento Agrário (MDA). ${ }^{11}$

Todos os produtos artesanais (especialmente bolsas e chapéus) do catálogo de coleções desenhado por estilistas de renome nacional (financiados pelo Pro- grama do MDA) e produzidos pelas artesãs da Artecoop e seus grupos de produção são comercializados pela Cooperunica $^{12}$. A Cooperunica recebe as encomendas e encaminha para a Cooperativa, que distribui os pedidos para as artesãs cooperadas e para seus grupos ou núcleos de produção nos povoados. Nem todas as trabalhadoras artesãs destes núcleos de produçao são membros da Cooperativa.

Segundo relato das artesãs, muitos problemas de gestão na comercialização dos produtos foram sanados com a criação da Cooperunica, que surgiu por iniciativa dos gestores do Programa Talentos do Brasil. Os produtos confeccionados em parceria com os estilistas ou designers e que levam a marca Linho dos Lençóis são comercializados em grandes centros urbanos nacionais.

Uma bolsa produzida pelas artesãs que é parte do catálogo da coleção do Programa Talentos do Brasil (MDA) pode alcançar valores superiores a $\mathrm{R} \$ 200,00$ ou $\mathrm{R} \$ 300,00$ no mercado de moda, sendo que na loja da Artecoop em Barreirinhas a bolsa abacaxi, por exemplo, custava, em janeiro de 2010, R \$86,00. Uma cópia de uma bolsa abacaxi da Artecoop produzida pelas artesãs não cooperadas pode ser vendida para os atravessadores pelo valor de $\mathrm{R} \$ 30,00$. Percebe-se que as artesãs cooperadas da Artecoop enfrentam uma competiçao no mercado local e que o produto artesanal que circula ao longo da cadeia e chega no mercado de moda nos grande centros urbanos adquire maior valor.

A análise do valor do produto artesanal é algo complexo e desafiador em uma abordagem da cadeia completa. Ele envolve os valores dos trabalhos dos extrativistas, das artesãs e das artesãs costureiras, assim como o trabalho dos designers. Envolve o valor da matéria-prima e seu custo ambiental, assim como o valor da cultura. Sem deixar de mencionar o significado que o consumidor - que nem sempre é quem compra - irá atribuir ao produto artesanal e natural durante seu uso.

Este produto artesanal das artesãs cooperadas que chega ao consumidor final em mercados distantes (grandes centros urbanos brasileiros) soma uma série de atividades de trabalho e de produção. A concepção do produto passa a ser uma tarefa dos designers que projetam produtos a serem produzidos de forma artesanal. Os designers projetam a partir de criação e reinterpretação, em uma forma de apropriação criativa, que pode ter por base pesquisa das iconografias e dos saberes tradicionais e pesquisa sobre a matéria-prima e as técnicas utilizadas. $\mathrm{O}$ trabalho do designer opera 
entre as pressões do mercado (necessidade de adequar o produto ao mercado da moda) e a herança do saber cultural presente na comunidade das artesãs.

Desde 2006, as artesãs da Artecoop realizam parceria com designers de renome nacional vinculados ao Programa Talentos do Brasil, patrocinado pelo Ministério do Desenvolvimento Agrário. Esta relação de trabalho e de produção entre artesã e designer resultou em duas coleções (acessórios: bolsas e chapéus etc.) assinadas pelos estilistas considerados autores (criadores) destas coleções. Os produtos destas coleções foram exibidos em importantes semanas de moda do Brasil e posteriormente comercializados em grandes centros urbanos, como, por exemplo, Rio Fashion Week e Capital Fashion Week.

Um dos focos das políticas de fomento é a adequação do produto ao mercado consumidor. A aliança entre artesanato e design torna-se um diferencial competitivo que possibilita agregar valor ao produto. Assim se constrói uma nova relação de trabalho entre o artesão e o designer no contexto da produção de artesanato.

Segundo o documento Artesanato: um Negócio Genuinamente Brasileiro, do SEBRAE Nacional (2008), "Aliar artesanato e design é uma maneira de estabelecer diálogo com o mercado consumidor, além de unir tradição e contemporaneidade". Neste documento, a consultora do SEBRAE Cristina Franco declara que "a principal função do designer é traduzir para o artesão as necessidades dos consumidores"; e o estilista mineiro Ronaldo Fraga destaca que "a relação entre o designer e o artesão tem de ser de troca": "Nós, os designers, atuamos como interlocutores entre a comunidade e o mercado" (Sebrae, 2008, p. 32 e 35).

Para nossa investigação, importa analisar a natureza e os significados desta relação de trabalho entre artesão e designer. Os relatos das artesãs revelam singularidades da relação e o impacto nos modos de criar e produzir.

As meninas mesmo elas criam [...]. Cada uma tem uma ideia. Porque o designer vem. Mas a gente já sabe de tudo. Eles vêm mesmo só para, ele fala assim monta isso monta aquilo (Artesã da Artecoop).

O trabalho junto com os estilistas. Eu avalio é só em termos de apoio. Porque ele vem de lá e trás algumas coisas que é necessária né. Chega passa serviço pra gente. A gente que faz tudo. Eles não faz nada. As vezes eu acho assim. Que nós. Eu acho assim que nós artesãs também pode ser uma estilista. (Artesã da Artecoop)

Antes do designer a gente mesmo criava as nossas peças e a gente foi aprendendo umas com as outras. Alguém aprendeu com alguém. Alguém que foi ensinando né.
Eu aprendi com as outras artesãs do povoado a fazer o artesanato de buriti. Quando o designer chega, eu até fui pra uma reunião em São Paulo no mês de outubro e eu disse pro pessoal do Projeto Talentos do Brasil, que eu não concordo com o que o estilista faz no povoado quando chega. Porque quando chega ele muitas vezes ele traz uma peça modelada e fazendo assim cria essa peça. Eles não querem saber da opinião da gente. Nós temos aqui peças muito mais bonitas do que as peças que o designer criou lá. Mas a importância do designer é que o acabamento fica muito perfeito. Então a peça pode ser assim... Mas o diferencial é o acabamento. $\mathrm{O}$ acabamento deles é bem feito. As vezes eu falo lá pra elas que eu não concordo é que eles chegam as vezes com um tipo de material. Por exemplo o couro. $\mathrm{O}$ couro na nossa região ele não tem. E eles chegam dizendo eu vou aplicar o couro nesta bolsa. A gente fica dizendo que não quer. Mas ele diz que só fica bonito se for com couro. (Artesã da Artecoop)

Esses relatos são por demais ricos com relação à natureza da relação de produção, a qual o estilista mineiro Ronaldo Fraga bem destacou que deveria ser de troca. Eles revelam que entre as artesãs cooperadas existe a consciência de suas próprias habilidades e capacidades criativas, a consciência da importância do uso de insumos naturais e provenientes da região. As artesãs também ressaltam os saberes e conhecimentos que os designers transmitem e sua aplicabilidade no acabamento e na qualidade do produto. Os depoimentos das artesãs deixam claro que elas possuem maior consciência com relação ao uso de matéria-prima da região, já os estilistas parecem estar mais preocupados com a inserção dos produtos no mercado de moda.

Os produtos das artesãs cooperadas da Artecoop vem tendo sucesso comercial. A Artecoop ganhou o Prêmio Top 100 do SEBRAE de Artesanato neste ano, além de ter seus produtos (acessórios: bolsas e chapéus) apresentados em diversas semanas de moda em grandes centros urbanos brasileiros, como Brasília, Rio de Janeiro e São Paulo. Dessa forma, pode-se dizer que o bom desempenho comercial dos produtos se deve à maior valorização da produção artesanal, em especial aquela feita a partir de matéria- prima natural, ou seja, a fibra do buriti. Trata-se de um produto artesanal e natural.

A economia do artesanato tem passado por diversas mudanças. A produção artesanal se volta cada vez mais para mercados novos e distantes e algumas políticas de fomento enfatizam o caráter de negócio da atividade e a importância de profissionalizar o artesão para transformá-lo em um pequeno empresário. A coordenadora nacional do programa de artesanato do SEBRAE declarou para o Jornal Valor Econômico: "O artesão tem de se perceber como empresário. A qualidade e a originalidade de seu trabalho é que garantirá avanços no faturamento" (Tiago, 2010). 
O maior contato dos trabalhadores e trabalhadoras da economia do artesanato com a economia de mercado tem provocado diversos impactos. Antes uma produção voltada para consumo próprio (bens utilitários) ou produção em pequena escala para mercado local, agora uma produção voltada para mercados mais amplos e distantes. O trabalho e a economia do artesanato entram em contato com questões que dizem respeito ao mundo empresarial, como qualidade do produto, adequação ao mercado, empreendedorismo, palavras-chave no cenário econômico atual.

Neste artigo, busca-se ver o produto e o seu produtor, as práticas sociais e as condições de vida e de trabalho das artesãs, o produto artesanal com seu valor sociocultural e econômico e a particularidade do fazer artesanal que utiliza as mãos e o cerébro para manusear a matéria-prima e imprimir uma forma ao produto.

\section{Considerações finais}

Nosso objetivo foi apresentar as singularidades da realidade socioeconômica e das transformações do mundo do trabalho artesanal com base na análise das relações de trabalho e de produção da Artecoop. Os dados parciais de pesquisa indicam mudanças e continuidades nesta realidade. As mudanças surgem ligadas tanto à dinâmica socioeconômica da atividade artesanal nesta região quanto aos impactos das relações de mercado e das ações das políticas de fomento.

Em diversas medidas, essas mudanças têm alterado os modos de ser e incorporado novas maneiras de fazer do artesanato produzido à base de fibra de buriti. Contudo, apesar dos avanços e da importância dessa atividade na sobrevivência das artesãs e na reprodução da cultura local, permanece a precariedade das condições de vida e de trabalho, as quais se encontram imersas na informalidade, ou seja, as trabalhadoras não possuem acesso aos direitos sociais, como férias, décimo terceiro e fundo de garantia, apenas trabalham para realizar a sua reprodução social e biológica diária. No trabalho de campo, constatou-se que muitas artesãs filiam-se ao Sindicato dos Trabalhadores Rurais (como agricultoras) ou ao Sindicato dos Pescadores (como marisqueiras) a fim de obter proteção social básica, mas, ao mesmo tempo, esta estratégia acarreta uma forma de invisibilidade do trabalho artesanal nas estatísticas oficiais.

Com relação aos impactos das políticas de fomento, em nossa análise destacamos os seguintes: o surgimento da ação cooperada com a organização das artesãs em cooperativa, ainda que número de artesãs associadas na Artecoop seja muito pequeno; uma maior consciência, entre as artesãs cooperadas, do preço justo e da importância de se preservar os buritizais, a qual se multiplica nos grupos de produção familiar e comunitário; uma maior profissionalização das artesãs cooperadas; a introdução da visão empreendedora e a busca de adequação do produto ao mercado.

As trabalhadoras artesãs cooperadas na Artecoop, imersas em redes de produção locais em condições de informalidade e precariedade, enfrentam diversos desafios, como: vencer os comerciantes atravessadores que dominam esta economia; realizar a gestão financeira e comercial da empresa cooperativa; superar as dificuldades na obtenção da matéria-prima e promover a preservação dos buritizais; enfrentar as dificuldades financeiras advindas das oscilações do mercado; garantir seu reconhecimento e valorização profissional; e garantir melhores condições de vida e de trabalho.

Consideramos um desafio das políticas de fomento articular as diversas ações voltadas pra o artesanato e garantir a valorização do produto e do seu produtor com o reconhecimento do trabalho do artesão. No nosso entender, é importante que o artesão tenha tanto a consciência do fazer artesanal quanto domínio e controle das etapas de criação e de produção artesanal.

Estas novas práticas sociais e econômicas do artesanato podem resgatar, modificar e recriar os valores tradicionais ligados à identidade do trabalho artesanal. Trata-se de um desafio conjugar nas ações de promoção do artesanato a geração de renda e a ampliação do mercado com o respeito aos artesãos e aos seus valores e saberes populares e culturais.

As artesãs cooperadas ainda representam um grupo quantitativamente muito pequeno em relação ao universo das artesãs desta região. A experiência das artesãs cooperadas da Artecoop imersas dentro do amplo universo da economia do artesanato possibilita reflexões sobre mudanças e desafios vividos pelos trabalhadores do artesanato. Buscamos destacar a inserção do trabalho e da produção artesanal nas redes de relações sociais, econômicas e institucionais, sobretudo a organização do trabalho artesanal em cooperativa e o seu acesso às atividades das políticas públicas de fomento, e de que forma seu produto circula ao longo da cadeia do artesanato e como esta cadeia se interliga a outras cadeias produtivas, como parte das novas configurações do trabalho e da produção artesanal em sua inserção na economia e na sociedade contemporânea.

A cooperativa na economia do artesanato tem suas particularidades. Ela tem importância social e econômica para este particular mundo do trabalho e de produção, e encontra-se imersa em redes de 
relações de competição e de cooperação, de subordinação e de dependência.

O caso da Artecoop suscita questões pertinentes aos dois tipos de cooperativas apresentados pelo sociólogo Jacob Carlos Lima (2004), quais sejam: a "lógica da solidariedade", em que a cooperação surge não apenas como um meio para atingir fins econômicos, mas sim perseguindo valores e interesses ideais como cooperativismo e solidariedade; e a "lógica empresarial", em que a cooperação é vista de forma instrumental como meio para atingir fins materiais ou fins econômicos e financeiros de forma competitiva,

Salientamos que a Artecoop é uma cooperativa de artesãs que não se encontra subordinada ou dependente de redes de subcontratação industrial. Mas o trabalho artesanal cooperado tem funcionalidade para o sistema econômico dominante e produz valor que é apropriado ao longo das relações com a indústria do turismo e a da moda. A Artecoop também não tem vínculos com o movimento e os ideais da economia solidária ou do movimento cooperativista.

A Artecoop é uma associação de artesãs autônomas que de certa forma incorpora a lógica empresarial, seja pela ênfase das políticas de fomento na visão empreendedora, seja pela intenção de transformar o artesão em um empresário. Verificamos que, se por um lado a Artecoop não é dependente direta de redes empresariais de subcontratação industrial, por outro lado existe uma dependência de políticas governamentais e de orgãos de fomento e uma subordinaçao à lógica de funcionamento das empresas capitalistas. Dentro do quadro de mutabilidade do artesanato, permanece como um desafio os artesãos e suas organizações coordenarem o 'processo de criação e produção’ e terem relativo domínio das demais atividades integrantes da cadeia de valor do artesanato.

\section{Referências}

AlVES, M. A.; TAVARES, M. A. A dupla face da informalidade do trabalho: autonomia ou precarização. In: ANTUNES, Ricardo (Org.) Riqueza e miséria do trabalho no Brasil. São Paulo: Boitempo, 2006.

ALVIM, Rosilene. Artesanato, tradição e mudança social: Um estudo a partir da arte do ouro de Juazeiro do Norte. In: RIBEIRO, Berta et al. (Orgs.). O artesão tradicional e seu papel na sociedade contemporânea. Rio de Janeiro: Funarte, 1983.

BOURDIEU, Pierre. As regras da arte: gênese e estrutura do campo literário. São Paulo: Companhia das Letras, 1996.

BOURDIEU, Pierre. A economia das trocas simbólicas. 5. ed. São Paulo: Perspectiva, 2004.

CANCLINI, Néstor G. Culturas híbridas: estratégias para entrar e sair da modernidade. São Paulo: Edusp, 2008.

KELlER, Paulo F. Cadeia de valor. In: CATTANI, A. D. Dicionário de trabalho e tecnologia. Porto Alegre: Ed. da UFRGS, 2006.

LIMA, Jacob C. Trabalho, autogestão e mercado: como ficam os trabalhadores. In: VIII CONGRESSO LUSO-AFRO-BRASILEIRO DE CIÊNCIAS SOCIAIS. Centro de Estudos Sociais, Coimbra, 16/17/18 set. 2004a.

LIMA, Jacob C. O trabalho autogestionário em cooperativas de produção: o paradigma revisitado. Revista Brasileira de Ciências Sociais, Anpocs, São Paulo, v. 19, n. 56, Out. $2004 \mathrm{~b}$.

LIMA, Jacob C. Artesanato: cinco pontos para discussão. Brasília: Ed. do Ministério da Cultura - Centro Nacional de Folclore e Cultura Popular, 2005.

MARX, Karl. O capital: crítica da economia política: livro 1 - o processo de produção do capital. 3. ed. Rio de Janeiro: Civilização Brasileira, 1975. V. 1, 2.
MDIC: Ministério do Desenvolvimento, Indústria e Comércio Exterior. Disponível em: <http://www.mdic.gov. $\mathrm{br} / \mathrm{sitio} /$ interna $/$ interna.php?area $=4 \& \mathrm{menu}=2046>$. Acesso em: 19 set. 2010.

MDIC-BRASIL. Programa do Artesanato Brasileiro. Brasília: MDIC-SDP, s/d.

MILLS, Wright. O ideal do artesanato. In: MILLS, Wright. Sobre o artesanato intelectual e outros ensaios. Rio de Janeiro: Jorge Zahar, 2009.

SEBRAE. Artesanato: um negócio genuinamente brasileiro. Brasília: Ed. do Sebrae Nacional, 2008.

SEBRAE. Cooperativas. Brasília: Ed. do SEBRAE/NA, 2009. (Série Empreendimentos Coletivos).

SENNETT, R. O artífice. Rio de Janeiro: Record, 2009. SITE: <http://www.ibge.gov.br/cidadesat/painel/painel.php?codmun=210170\#>. Acesso em: 13 mar. 2011. SITE: <http://www.camara.gov.br/sileg/Prop_Detalhe.asp?id=260275>. Acesso em: 30 nov. 2010.

SITE: <http://www.cooperunica.com.br/>. Acesso em: 09 maio 2010.

TIAGO, Ediane. Programas do Sebrae pretendem agregar valor à arte regional: profissionalizar é a ordem no universo dos artesãos. Jornal Valor Econômico, Especial: Pequenas e Médias Empresas (Gestão), sexta-feira, 30 de abril de 2010, p. 5.

UNIDO. Creative industries and micro \& small scale enterprise development: a contribution to poverty alleviation. Vienna, Austria: United Nations Industrial Development Organization, 2002.

VIVES, Vera de. A beleza do cotidiano. In: RIBEIRO, Berta et al. $\mathrm{O}$ artesão tradicional e seu papel na sociedade contemporânea. Rio de Janeiro: FUNARTE-INF, 1983. 


\title{
Handicraft and cooperative work: realities, changes and challenges
}

\begin{abstract}
This article aims to show the singularities of the socioeconomic reality and the changes in the handicraft work through case study of the Cooperative of Craftswomen of Lençóis Maranhenses (Artecoop) in the Barreirinhas city, state of Maranhão - Brazil. It makes an analysis of labor relations and production of craftswomen cooperatives and their networks of relationships rooted in socioeconomic and institutional relations. It analyses the government policies and the inclusion of the craftswomen and their products in the capitalism market and the value chain of crafts. The introduction of the entrepreneurial vision, the importance of adapting the product to market and the cooperative as a way (company) to achieve competitiveness are issues highlighted. To what extent these changes alter the identity of the handicraft work? How the craftswomen, producing handicrafts to live in informal and precarious situation, face the challenge of becoming entrepreneurs through cooperative action?
\end{abstract}

Keywords: handicraft; cooperative; handmade work; handicraft economy; Maranhão.

\section{Trabajo artesanal y cooperado: realidades, cambios y retos}

\section{Resumen}

El artículo tiene como objetivo presentar las singularidades de la realidad socioeconómica y de los cambios del trabajo de artesanía a partir del estudio de caso de la "Cooperativa das Artesãs dos Lençóis Maranhenses” (Artecoop), en el municipio de Barreirinhas - MA. Se realiza un análisis de las relaciones de trabajo y de producción de las artesanas cooperadas y su establecimiento en redes de relaciones socioeconómicas e institucionales. Analiza el impacto de las intervenciones políticas gubernamentales, de la inserción de las artesanas, de sus productos en el mercado capitalista y en la cadena de valor de la artesanía. La introducción de una visión empresarial, la importancia de adecuar el producto al mercado y a la cooperativa como un medio (empresa) a fin de alcanzar la competitividad son puntos que se ponen en relieve. ¿En qué medidas estos cambios alteran la identidad del trabajo artesano? ¿Cómo los artesanos que trabajan en la informalidad y en la precariedad enfrentan el reto de convertirse en emprendedores a partir de una acción cooperada?

Palabras claves: artesanía; cooperativa; trabajo artesanal; economía de la artesanía; Maranhão.

Data de recebimento do artigo: 30-11-2010

Data de aprovação do artigo: 31-03-2011 
ANEXO: A CADEIA DE VALOR DO ARTESANATO

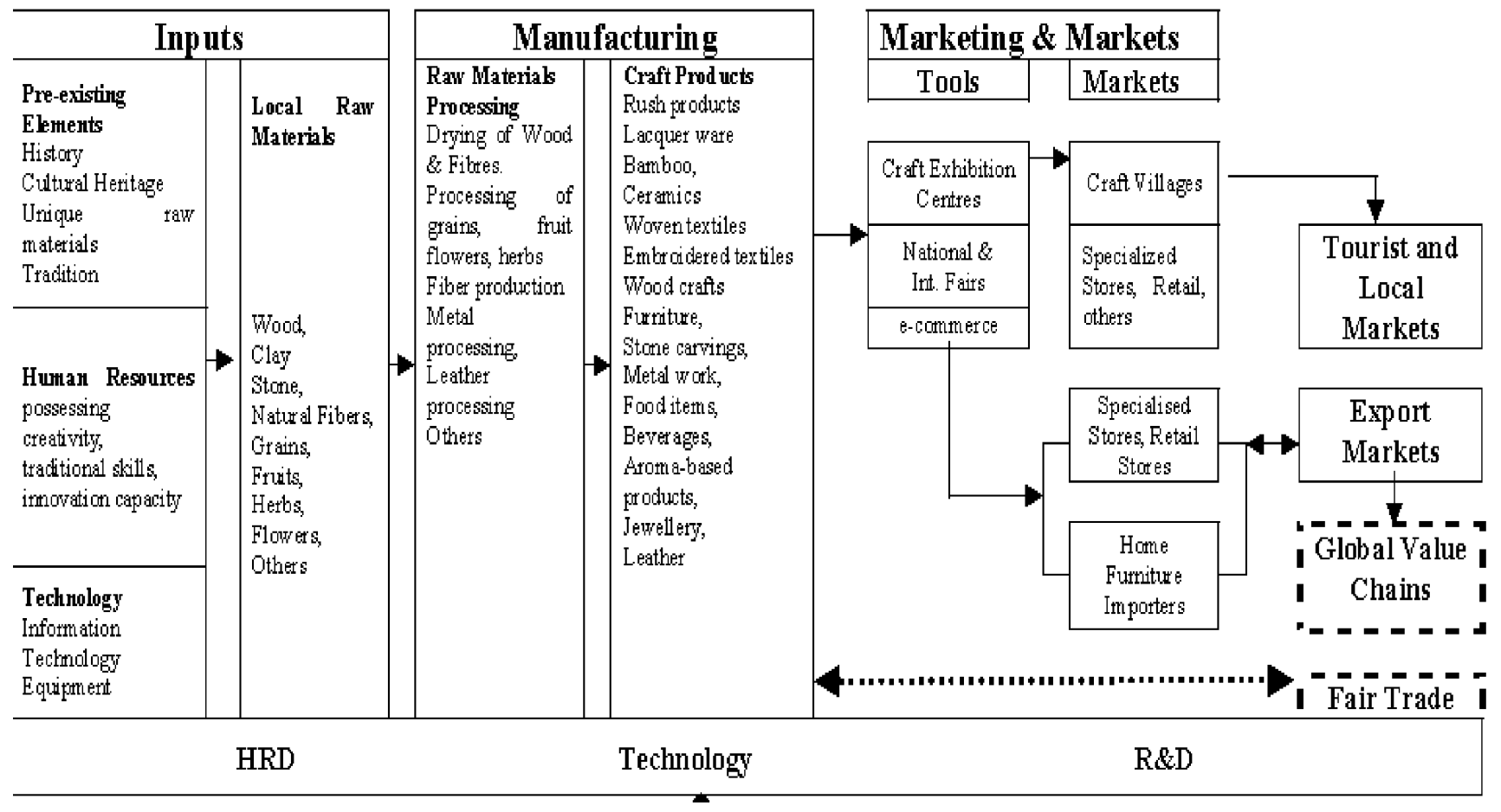

Fonte: UNIDO (2002, p. 25). 